\title{
Unsafe Disposal of Child Faeces: A Community-based Study in a Rural Block in West Bengal, India
}

\author{
Preeti PS, Sanjaya Kumar Sahoo, Dhiraj Biswas, Aparajita Dasgupta \\ Department of Preventive and Social Medicine, All India Institute of Hygiene and Public Health, West Bengal, India
}

Objectives: A clean India is the responsibility of all Indians. One of the objectives of the Swachh Bharat Abhiyan (Clean India Initiative) is to bring about behavioural changes regarding healthy sanitation practices. While large-scale programs in India have increased latrine coverage, they have to some extent failed to bring behavioural changes ensuring optimal latrine use, including the safe disposal of child faeces, which is a significant source of exposure to faecal pathogens. Hence, this study was done to explore child faeces disposal practices in rural West Bengal and to elicit the determinants of unhygienic faeces disposal.

Methods: Data collection was done using an interview method among the mothers of 502 under- 5 children, following a pre-designed, semi-structured schedule during house-to-house visits in a set of villages in the Hooghly district of West Bengal.

Results: The prevalence of unsafe disposal of child faeces was $72.4 \%$, and maternal education, per capita income, and water source were found to be significantly associated with unsafe child faeces disposal.

Conclusions: This study draws attention to the unsafe disposal of child faeces in this area of India and raises questions about the efficiency of sanitation campaigns in rural India that focus on expanding coverage rather than emphasizing behavioural changes, which are crucial to ensure the safe disposal of child faeces. Thus, it is urgently necessary to strengthen efforts focusing on behavioural changes regarding the safe disposal of child faeces in order to minimise adverse health outcomes.

Key words: Child, Sanitation, Prevalence, Rural health

\section{INTRODUCTION}

One of the targets included in the 2015 Sustainable Development Goals is "By 2025, no one practices open defecation"

Received: February 20, 2016 Accepted: September 8, 2016

Corresponding author: Preeti PS, MD

110 Chittaranjan Avenue, Kolkata-700073, West Bengal, India

Tel/Fax: +91-9051185752

E-mail: drpreeti186@gmail.com

This is an Open Access article distributed under the terms of the Creative Commons Attribution Non-Commercial License (http://creativecommons.org/licenses/by$\mathrm{nc} / 4.0 /$ ) which permits unrestricted non-commercial use, distribution, and reproduction in any medium, provided the original work is properly cited.
[1]. As defined by the Joint Monitoring Programme (JMP), an improved sanitation facility is one that hygienically removes human excreta from human contact [2]. The latest JMP report stated that $64 \%$ of the global population had access to improved sanitation in 2012 [2], which means that 2.5 billion individuals still lacked improved sanitation; of these, one billion practiced open defecation [2].

In India, improved sanitation is a huge challenge, as $50 \%$ of the population still practices open defecation and only $35 \%$ of the population uses improved sanitation [2]. This gap has led to large-scale interventions to increase sanitation coverage, the latest of which is the Swachh Bharat Abhiyan (Clean India Initiative), the brainchild of the Prime Minister of India [3]. One 
of its objectives is to bring about behavioural changes regarding healthy sanitation practices [3]. While large-scale programs in India have increased latrine coverage, they have to some extent failed to bring changes in behaviour ensuring optimal latrine use.

Although the impacts of poor sanitation and hygiene are often measured by their effects on children, most sanitation and hygiene interventions target adults. The effective disposal of child faeces is an essential indicator for an open defecationfree certification under the Swacch Bharat Abhiyan [4]. The unsafe disposal of child faeces is a common practice in India, and is a significant source of exposure to faecal pathogens. In fact, the unsanitary disposal of child faeces may have substantial impacts on the health of children, including a higher prevalence of diarrheal disease [5]. In a questionnaire administered by the National Family Health Survey (NFHS), West Bengal was found to have low percentage of safe child stool disposal, with only $18 \%$ of stools being disposed of safely [6]. According to the World Health Organization, most diarrheal deaths in the world (88\%) are caused by unsafe water, sanitation, or hygiene. More than $99 \%$ of these deaths are in developing countries, and approximately eight of every 10 deaths are children [7].

In many low-income settings, diapers, clothes, and potties are rarely available or rarely used, making the hygienic collection of young children's faeces difficult; if collected, such faeces are often disposed of in a manner that does not prevent further exposure of household members or the contamination of water sources. Even in households that have access to latrines, children's faeces are often not collected or disposed of safely in latrines.

Very few studies are available addressing this issue globally, and even fewer studies have addressed India, where the unsafe disposal of child faeces is a common sanitation problem that contributes to adverse health outcomes. Most studies have only focused on the problems of open defecation and other issues related to sanitation

Hence, this study was performed with the objective of exploring child faeces disposal practices in rural West Bengal and to elicit the determinants of such practices.

\section{METHODS}

The study was cross-sectional, community-based, and was conducted in a rural block of West Bengal over a period of two months, from December 2014 to January 2015.
The necessary sample size was calculated based on an estimated prevalence of unsafe child faeces disposal in India of $79 \%$ (NFHS-3) [8]. Based on this prevalence figure, the necessary sample size was calculated to be 509 , but only 502 subjects were included in the study, as households were excluded if no adult member of the family was present at the time of the interview. Household visits and face-to face interviews with adult family members were performed.

In order to collect the necessary information, a predesigned structured questionnaire was prepared by the researchers after a meticulous literature review and consultation with experts in this field; the questionnaire was again rechecked by the experts in order to ascertain its reliability and to remove any ambiguity. The face validity of each item and the content validity of each domain of the questionnaire was also determined [9]. The questionnaire was expected to reveal the necessary information according to its stated objectives. The questionnaire was drawn up in English, translated into Bengali, keeping semantic equivalence, and back-translated into English by two language experts to check the translation. The questionnaire was pre-tested and modified accordingly, and was again translated into Bengali and back-translated into English by the language experts. The survey items included assessments of demographic, socioeconomic, and household characteristics.

A 2-stage random sampling procedure was followed to select the study participants. In the first stage, two gram panchayats were selected randomly from a sample of six gram panchayats (each gram panchayat consists of 8 to 9 villages). In the second stage, three villages were randomly selected from each gram panchayat. The required sample was randomly selected from six villages using the proportionate probability sampling technique. Line listing of all under- 5 children was done, and 509 children were selected by simple random sampling. A total of 502 children were ultimately enrolled in this study.

\section{Statistical Analysis}

Statistical analysis was carried out using SPSS version 20.0 (IBM Corp., Armonk, NY, USA). Standard descriptive analysis was carried out, followed by bivariate analysis and multivariate analysis using binomial logistic regression, adjusting for covariates considered to influence the outcome. Unsafe disposal of child faeces was defined as the disposal of faeces in any site other than a sanitary latrine. 
Table 1. Socioeconomic, demographic, and household characteristics of the study participants $(n=502)$

\begin{tabular}{|c|c|}
\hline Characteristics & n (\%) \\
\hline \multicolumn{2}{|l|}{ Children } \\
\hline Pre-ambulatory & $184(36.6)$ \\
\hline Ambulatory & $318(63.3)$ \\
\hline \multicolumn{2}{|l|}{ Age of mother (y) } \\
\hline $18-23$ & $157(31.3)$ \\
\hline $24-29$ & $224(44.6)$ \\
\hline $30-35$ & $121(24.1)$ \\
\hline \multicolumn{2}{|l|}{ Age of father (y) } \\
\hline $20-29$ & $130(25.9)$ \\
\hline $30-39$ & $177(35.3)$ \\
\hline $40-49$ & 195 (38.8) \\
\hline \multicolumn{2}{|l|}{ Level of education of the mother } \\
\hline Illiterate & $62(12.4)$ \\
\hline Primary school & $95(18.9)$ \\
\hline Middle school & $140(27.8)$ \\
\hline Secondary school & $87(17.4)$ \\
\hline Higher secondary school & $70(13.9)$ \\
\hline Graduated secondary school or above & $48(9.6)$ \\
\hline \multicolumn{2}{|l|}{ Level of education of father } \\
\hline Illiterate & $2(0.4)$ \\
\hline Primary school & $49(9.7)$ \\
\hline Middle school & $159(31.7)$ \\
\hline Secondary school & $154(30.7)$ \\
\hline Higher secondary school & $86(17.1)$ \\
\hline Graduated secondary school or above & $52(10.4)$ \\
\hline \multicolumn{2}{|c|}{ Per capita income (Rs, modified BG Prasad scale 2014) } \\
\hline 2786-5570 (41.4-82.9 USD) & $166(33.1)$ \\
\hline $1671-2785$ (24.8- 41.4 USD) & $170(33.9)$ \\
\hline 836-1670 (12.4-24.8 USD) & $112(22.3)$ \\
\hline <836 (12.4 USD) & $54(10.8)$ \\
\hline \multicolumn{2}{|l|}{ Sanitary latrine } \\
\hline Present & $379(75.5)$ \\
\hline Absent & $123(24.5)$ \\
\hline \multicolumn{2}{|l|}{ Source of water } \\
\hline On the premises of the residence & $223(44.4)$ \\
\hline Outside the premises of the residence & $279(55.5)$ \\
\hline
\end{tabular}

Rs, Indian rupee.

\section{RESULTS}

Of the 502 children who were enrolled in the study, $36.6 \%$ were pre-ambulatory and $63.3 \%$ were ambulatory. Of their mothers, $12.4 \%$ were illiterate, while $27.8 \%$ had completed middle school, and $33.9 \%$ belonged to class III in terms of their socioeconomic status (BG Prasad scale 2014) (Table 1).
Table 2. Distribution of defecation and disposal sites

\begin{tabular}{lcc}
\hline & $\begin{array}{c}\text { Pre-ambulatory } \\
(\mathbf{n}=\mathbf{1 8 4})\end{array}$ & $\begin{array}{c}\text { Ambulatory } \\
(\mathbf{n}=\mathbf{3 1 8})\end{array}$ \\
\hline $\begin{array}{l}\text { Defecation site } \\
\text { Potty }\end{array}$ & $50(27.2)$ & $41(12.9)$ \\
Nappy & $33(17.9)$ & $12(3.8)$ \\
Ground (in compound) & $69(37.5)$ & $132(41.5)$ \\
Ground (in household) & $32(17.4)$ & $85(26.7)$ \\
Latrine (ambulatory children) & - & $48(15.1)$ \\
Disposal site & & \\
Latrine & $50(27.1)$ & $82(25.8)$ \\
Garbage & $85(46.1)$ & $151(47.5)$ \\
Field & $27(14.7)$ & $71(22.3)$ \\
Pond & $18(9.9)$ & $14(4.4)$ \\
$\quad$ Washed (pre-ambulatory children) & $4(2.2)$ & - \\
\hline
\end{tabular}

Values are presented as number (\%).

We found the prevalence of unsafe disposal of child faeces to be $72.4 \%$. The defecation and disposal sites reported for the last time the children defecated are listed in Table 2. Most children were reported to defecate on the ground, either inside the home (17.4\%) or compound (37.5\%) for pre-ambulatory children, or inside the compound for ambulatory children (41.5\%). Only $15.1 \%$ of ambulatory children defecated in a latrine.

The faeces of most children were ultimately disposed of in the household's solid waste disposal site, typically located outside the house at the rear of the compound, both for pre-ambulatory (46.1\%) and ambulatory (47.5\%) children. Overall, the faeces of only $27.5 \%$ of children were reported to have been safely disposed of, which was defined as either directly defecating in a latrine or faeces being transferred into a latrine. Safe disposal of child faeces only occurred in households that owned latrines $(n=449)$. However, latrine ownership was no guarantee of safe disposal of child faeces; the faeces of only $27.6 \%$ of children from the $89.4 \%$ of households with latrines were reported to be safely disposed of.

In the regression analysis, the mother's education (odds ratio [OR], 3.8; 95\% confidence interval [Cl], 2.5 to 5.8), per capita income (OR, 5.6; 95\% Cl, 3.4 to 9.0), and water source (OR, 6.2; $95 \% \mathrm{Cl}, 4.0$ to 9.8 ) were found to be significantly associated with unsafe child faeces disposal (Table 3 ).

\section{DISCUSSION}

This study reported the defecation and disposal practices of 502 children under five years of age in rural West Bengal, to- 
Table 3. Bivariate analysis assessing the associations of socioeconomic, demographic, and household characteristics with the unsafe disposal of child faeces ${ }^{1}$

\begin{tabular}{|c|c|c|c|}
\hline Variables & n (\%) & OR $(95 \% \mathrm{CI})$ & $\begin{array}{c}\text { Adjusted } \\
\text { OR }(95 \% \text { CI })^{2}\end{array}$ \\
\hline \multicolumn{4}{|l|}{ Children } \\
\hline Pre-ambulatory & $184(36.6)$ & $2.2(0.8,2.9)$ & $1.6(0.5,2.2)$ \\
\hline Ambulatory & $318(63.3)$ & 1.0 (reference) & 1.0 (reference) \\
\hline \multicolumn{4}{|l|}{ Education of mother } \\
\hline $\begin{array}{l}\text { Middle school and } \\
\text { below }\end{array}$ & $297(59.1)$ & $3.8(2.5,5.8)$ & $1.4(1.1,2.9)$ \\
\hline Above middle school & $205(40.8)$ & 1.0 (reference) & 1.0 (reference) \\
\hline \multicolumn{4}{|l|}{ Education of father } \\
\hline $\begin{array}{l}\text { Middle school and } \\
\text { below }\end{array}$ & $209(41.6)$ & $1.5(1.0,2.3)$ & $1.3(0.8,1.7)$ \\
\hline Above middle school & $293(58.3)$ & 1.0 (reference) & 1.0 (reference) \\
\hline \multicolumn{4}{|l|}{$\begin{array}{l}\text { Per capita income } \\
\text { (Rs, modified BG } \\
\text { Prasad scale 2014) }\end{array}$} \\
\hline$\leq 1600$ ( $\leq 23.9$ USD) & $270(53.7)$ & $5.6(3.4,9.0)$ & $4.7(2.9,7.6)$ \\
\hline >1600 (>23.9 USD) & $232(46.2)$ & 1.0 (reference) & 1.0 (reference) \\
\hline \multicolumn{4}{|l|}{ Latrine } \\
\hline Absent & $53(10.5)$ & $1.7(0.8,3.5)$ & $0.6(0.4,1.7)$ \\
\hline Present & $449(89.4)$ & 1.0 (reference) & 1.0 (reference) \\
\hline \multicolumn{4}{|l|}{ Source of water } \\
\hline Outside the premises & $279(55.5)$ & $6.2(4.0,9.8)$ & $5.6(2.9,8.3)$ \\
\hline Inside the premises & $223(44.4)$ & 1.0 (reference) & 1.0 (reference) \\
\hline
\end{tabular}

$\mathrm{OR}$, odds ratio: $\mathrm{Cl}$, confidence interval; $\mathrm{Rs}$, Indian rupee.

1 Unsafe disposal of child faeces was defined as disposal of faeces in any site other than a sanitary latrine.

${ }^{2}$ Adjusted model included all variables in the tables as covariates.

gether with the factors associated with these practices. We found that most child faeces were disposed of unsafely, even in households with latrines.

The prevalence of safe child faeces disposal found in this study is reasonably similar to the prevalence reported in the latest NFHS-3 (2005-2006), which reported that throughout India, 79.0\% percent of child faeces were disposed of unsafely [8]. Additionally, in the NFHS-3 survey, West Bengal was found to have a low percentage of safe child stool disposal, with only $18 \%$ of stools being disposed of safely [8]. Another such study done in rural Orissa, India reported a very high prevalence (81.4\%) of unsafe child faeces disposal [10]. The unsafe disposal of child faeces in latrines was found to be common in studies reporting on practices in Madagascar, Nepal, and Ethiopia [11-13].

However, the prevalence of safe child faeces disposal was found to be $67 \%$ in Zambia [14], 70\% in Kenya [15], 75\% in Uganda [16], and 79\% in Malawi [17] which are higher values than those obtained in this study. A study conducted in 24 countries revealed that over $50 \%$ of households in 14 of the 24 countries did not dispose the faeces of the child into any kind of toilet or latrine; that is, the faeces were unsafely disposed of [18].

Our study revealed that most child faeces ended up in the household waste disposal site. The waste materials therefore accumulate for many days, and when little space is left, they are burnt, giving off thick black fumes and resulting in air pollution. Additionally, the proximity of the site to the households may increase the risk in comparison to open defecation sites, which are typically more distant. The findings of our study corroborate those of the NFHS-3 (2005-2006) survey in West Bengal where the main disposal methods were found to be leaving the faeces in an open field (14.7\%) and disposing of them in the garbage (32.1\%) for pre-ambulatory children, whereas among ambulatory children, $16.9 \%$ had faeces disposed of in open fields and $37.7 \%$ in the garbage [8].

Another study reported that $42 \%$ of children's stools were left in the open or not disposed of, while $14.08 \%$ were thrown into the garbage, and only a very small proportion (1.11\%) were buried [13]. A study conducted in rural Orissa, India similarly reported that the faeces of most children were ultimately disposed of in the household's solid waste disposal site [10].

In a multivariate regression model after adjusting for other variables, the current study showed an inverse association of the unsafe disposal of child faeces with access to water within the compound, which is similar to findings reported from Burkina Faso [19]. In that study, it was hypothesized that such an association could be due to mothers in households with improved water sources wanting to conform to better standards of hygienic behaviour or having more time to carry out safer behaviours [19]. A possible explanation for this would be that accessibility of water within the premises of the household makes safe waste disposal more convenient for the mothers, who generally have to carry the water from the water source to the toilets. A study revealed that a piped water supply and improved latrines had a significant association with safe child faeces disposal practices [20]. The findings of our study contradict those of another study showing that the availability of an improved water supply was not significantly associated with safe child faeces disposal [13].

The mother's education was found to be inversely associated with unsafe child faeces disposal, in agreement with the findings of the NFHS-3 (2005-2006), in which it was reported that stools were disposed of safely for $61 \%$ of the children of moth- 
ers with 12 or more years of education, compared with only $9 \%$ of the children of mothers with no education [8]. A study in Ethiopia similarly reported that the odds of practicing safe disposal of child faeces increased with the level of mothers' education; for mothers who had not obtained any formal education, the prevalence of safe child faeces disposal was $28.34 \%$, whereas it was $78.14 \%$ among mothers who had obtained higher education [13]. A Kenyan study also showed that higher levels of maternal education were associated with greater levels of safety in the disposal of children's stools [15] . This association can be satisfactorily explained by the fact that educated mothers are clearly aware of the deleterious effects of unsafe faeces disposal and therefore practice safe disposal [21].

According to the NFHS-3 report [8], stools were safely disposed of for $65 \%$ of children living in households with higher socioeconomic status, compared with only $4 \%$ of children living in lower socioeconomic status households; our study likewise found an association between the unsafe disposal of child faeces and low socioeconomic status of the family. Similarly, an Ethiopian study found that households from higher wealth quintiles were more likely to practice safe disposal of child faeces than households from the poorest wealth quintile [13]. More affluent households were more likely to have improved sanitation and a better standard of living that might motivate them to dispose of child faeces safely [22].

In this study, even among households with improved toilets or latrines, unsafe child faeces disposal behaviour was reported. This finding is consistent with other studies that have similarly reported unsafe faeces disposal among households with latrines $[12,14,15,17]$. This clearly indicates that the focus of interventions must shift from coverage to behavioural changes. However, a study in Ethiopia and South Africa found that households with an improved latrine had a higher likelihood of practicing safe disposal of child faeces [13,22].

This study has some limitations. First, it has all the disadvantages of any cross-sectional study; namely, the temporal relationship between the outcome and independent variables could not be established. Mothers' knowledge of the consequences of unsafe disposal of child faeces was not evaluated in this study. Moreover, the study may be susceptible to courtesy and recall bias, as the data dealt with reported practices rather than direct observation $[23,24]$.

In conclusion, the practice of unsafe child faeces disposal was found to be common. This study draws attention to the unsafe disposal of child faeces in this area of India and raises questions about the efficiency of sanitation campaigns in rural India that focus on expanding coverage rather than emphasizing behavioural changes, which are crucial in ensuring the safe disposal of child faeces. Thus, it is urgently necessary to strengthen efforts focusing on behavioural changes regarding the safe disposal of child faeces in order to minimise adverse health outcomes. Nevertheless, it is vital to explore possible ways of incorporating child sanitation into existing interventions that target the caregivers of young children and to conduct basic research to understand the behavioural drivers and hurdles in safe child faeces disposal.

\section{CONFLICT OF INTEREST}

The authors have no conflicts of interest associated with the material presented in this paper.

\section{ORCID}

\section{Preeti PS http://orcid.org/0000-0003-0393-3626}

\section{REFERENCES}

1. United Nations. Sustainable development knowledge platform: goal 6; 2015 [cited 2016 Sep 26]. Available from: https:// sustainabledevelopment.un.org/sdg6.

2. World Health Organization. Progress on and drinking water and sanitation; 2014 [cited 2016 Sep 15]. Available from: http://apps.who.int/iris/bitstream/10665/112727/1/97892 41507240_eng.pdf?ua $=1$.

3. Ministry of Urban Development (India). Guidelines for Swachh Bharat Mission (Gramin); 2014 [cited 2016 Sep 26]. Available from: http://phed.bih.nic.in/Docs/Guidelines-Swachh-BharatAbhiyan.pdf.

4. Government of India Ministry of Urban Development. Draft guidelines for Swachh Bharat Mission (SBM); 2014 [cited 2016 Sep 26]. Available from: http://nswaienvis.nic.in/PDF/Guidelines\%20for\%20Swaccha\%20Bharat\%20Mission.pdf.

5. Fischer Walker CL, Perin J, Aryee MJ, Boschi-Pinto C, Black RE. Diarrhea incidence in low- and middle-income countries in 1990 and 2010: a systematic review. BMC Public Health 2012; 12:220.

6. United Nations Children's Fund. Child feces disposal in India; 2015 [cited 2016 Sep 9]. Available from: https://www.wsp.org/ sites/wsp.org/files/publications/WSP-India-CFD-Profile.pdf. 
7. World Health Organization. Global health risks: mortality and burden of disease attributable to selected major risks; 2009 [cited 2016 Sep 9]. Available from: http://www.who.int/health info/global_burden_disease/GlobalHealthRisks_report_full. pdf.

8. International Institute for Population Sciences. National family health survey (NFHS-3), 2005-06: India; 2007 [cited 2016 Sep 9]. Available from: http://dhsprogram.com/pubs/pdf/FRIND3/ FRIND3-Vol1andVol2.pdf.

9. Fitzner K. Reliability and validity: a quick review. Diabetes Educ 2007;33(5):775-780.

10. Majorin F, Freeman MC, Barnard S, Routray P, Boisson S, Clasen T. Child feces disposal practices in rural Orissa: a cross sectional study. PLoS One 2014;9(2):e89551.

11. United Nations Children's Fund. Child feces disposal in Madagascar; 2014 [cited 2016 Sep 9]. Available from: http://www. wsp.org/sites/wsp.org/files/publications/WSP-MadagascarCFD-Profile.pdf.

12. United Nations Children's Fund. Child feces disposal in Nepal; 2015 [cited 2016 Sep 9]. Available from: http://www.wsp.org/ sites/wsp.org/files/publications/WSP-Nepal-CFD-Profile.pdf.

13. Azage $M$, Haile D. Factors associated with safe child feces disposal practices in Ethiopia: evidence from demographic and health survey. Arch Public Health 2015;73:40.

14. United Nations Children's Fund. Child feces disposal in Zambia; 2014 [cited 2016 Sep 9]. Available from: http://www.wsp. org/sites/wsp.org/files/publications/WSP-Zambia-CFD-Profile.pdf.

15. United Nations Children's Fund. Child feces disposal in Kenya; 2014 [cited 2016 Sep 9]. Available from: http://wsp.org/sites/ wsp.org/files/publications/WSP-Kenya-CFD-Profile.pdf.

16. United Nations Children's Fund. Child feces disposal in Ugan- da; 2014 [cited 2016 Sep 9]. Available from: http://www.wsp. org/sites/wsp.org/files/publications/WSP-Uganda-CFD-Profile.pdf.

17. United Nations Children's Fund. Child feces disposal in Malawi; 2014 [cited 2016 Sep 9]. Available from: https://www.wsp. org/sites/wsp.org/files/publications/WSP-Malawi-CFD-Profile. pdf.

18. Loughnan L, Rand E, Reese H, Maule L, Dooley T. Child feces disposal practices in 24 countries [cited 2016 Sep 9]. Available from: http://whconference.unc.edu/files/2014/10/rand.pdf.

19. Traoré E, Cousens S, Curtis V, Mertens T, Tall F, Traoré A, et al. Child defecation behaviour, stool disposal practices, and childhood diarrhoea in Burkina Faso: results from a case-control study. J Epidemiol Community Health 1994;48(3):270-275.

20. Curtis V, Schmidt W, Luby S, Florez R, Touré O, Biran A. Hygiene: new hopes, new horizons. Lancet Infect Dis 2011;11(4): 312-321.

21. Mwambete KD, Joseph R. Knowledge and perception of mothers and caregivers on childhood diarrhoea and its management in Temeke municipality, Tanzania. Tanzan J Health Res 2010;12(1):47-54.

22. Phaswana-Mafuya N, Shukla N. Factors that could motivate people to adopt safe hygienic practices in the Eastern Cape Province, South Africa. Afr Health Sci 2005;5(1):21-28.

23. Manun'Ebo M, Cousens S, Haggerty P, Kalengaie M, Ashworth $A$, Kirkwood B. Measuring hygiene practices: a comparison of questionnaires with direct observations in rural Zaïre. Trop Med Int Health 1997;2(11):1015-1021.

24. Curtis V, Cousens S, Mertens T, Traore E, Kanki B, Diallo I. Structured observations of hygiene behaviours in Burkina Faso: validity, variability, and utility. Bull World Health Organ 1993; 71(1):23-32. 